\title{
Obsessive Compulsive Disorder treatment in patients with Down syndrome: A case series
}

\author{
Bruce Sutor MD, Mark R. Hansen MD, and John L. Black MD \\ Department of Psychiatry and Psychology, Mayo Clinic, Rochester, MN USA
}

\begin{abstract}
In this case series we report four cases of patients with Down syndrome with symptoms consistent with obsessive compulsive disorder. Each patient experienced substantial reduction in compulsive behaviors with pharmacotherapy of an SSRI alone or with the addition of risperidone to SSRI therapy. None of the patients experienced significant side effects. This small case series supports the use of these medications in the treatment of co-morbid obsessive compulsive disorder in patients with Down syndrome.
\end{abstract}

Keywords: Case series, Down syndrome, mental disorders, obsessive compulsive disorder, pharmacotherapy

Down syndrome is a commonly occurring chromosomal disorder that is associated with psychiatric co-morbidity in 28.9\% of cases (Prasher, 1995). Prevalence estimates for Obsessive Compulsive Disorder (OCD) within the Down syndrome population vary from $0.8 \%$ (Myers and Pueschel, 1991 ) to $4.5 \%$ (Prasher, 1995) with ordering and tidiness being the most commonly presenting behaviors (Prasher and Day, 1995). Obsessional slowness has been described in patients with Down syndrome (Charlot et al., 2002), and it has been postulated that compulsive behaviors may be a part of the behavioral presentations of some patients with Down syndrome (Evans and Gray, 2000).

Serotonin Specific Reuptake Inhibitors (SSRIs) have been the mainstays of pharmacologic treatment of OCD in nondevelopmentally disordered patients (Greist et al., 1995). When SSRIs alone do not substantially reduce symptoms, neuroleptics have been shown to be effective 'add-on' therapies in treatment refractory OCD patients (McDougle et al., 2000).

Little is known about the pharmacologic management of OCD in patients with Down syndrome. SSRIs have been reported to be effective treatments of OCD in developmentally disordered adults (Barak et al., 1995; Bodfish and Madison, 1993; Cook et al., 1990; Wiener and Lamberti, 1993). Specific to Down syndrome, O'Dwyer (O'Dwyer, 1992) reported two cases of OCD in patients with Down syndrome, one of whom had a partial response to fluvoxamine $200 \mathrm{mg}$, and another patient who failed successive trials of clomipramine $150 \mathrm{mg}$ and fluoxetine 40 mg. Raitasuo et al. (Raitasuo et al., 1998) reported a case of a patient with Down syndrome with anorexia nervosa, major depression, and OCD who had reduction in OCD symptoms with citalopram $40 \mathrm{mg}$.

In this article, we report a case series of four adult patients with Down syndrome with co-morbid behaviors consistent with OCD who were treated with SSRIs alone or with risperidone augmentation therapy. Each patient had a significant improvement in OCD symptoms and did not experience extra-pyramidal symptoms (EPS) or tardive dyskinesia (TD).

\section{Case example}

Ms A is an adult female with Down syndrome, insulin dependent diabetes mellitus, and a history of grand mal seizures that occurred during periods of severe hypoglycemia. She was on a stable dose of phenytoin for seizure prophylaxis. The patient had been a group home resident for 15 years, having done well there behaviorally over the course of this time. She was employed as a cleaner for a nearby hotel and was well liked by other residents, group home staff, and her employer. She was described by staff as having a "sunny disposition" and had no history of depression, aggression, anxiety, or psychosis. She was somewhat orderly and had a daily routine that could be easily disrupted without incident, and no other symptoms consistent with OCD.

At age 38 staff began to note increasing verbal aggression and anxiety whenever her daily routine was disrupted. Whenever she would notice that the living room furniture was moved she would place the furniture back into its 
usual position before she would go on to other activities. She began brushing her teeth for 15 minutes a day and was observed touching each of her clothes hangers as she prepared to dress each morning.

Over the next two years she became physically combative with staff and peers whenever her routine was upset or when attempts were made to divert her behaviors. There were no changes in her work, home, or family circumstances that could account for the behavior changes and neither the patient nor staff could identify any precipitating events. She did not display any depressive or psychotic symptoms but the staff noted cognitive slowing and short-term memory difficulties. Her blood glucose levels remained under moderately good control, she experienced no seizures, and there were no changes to her medications or her overall medical health. Eventually her behavior became so severe that her employment was threatened and staff began considering alternative group home placement.

Laboratory evaluation including electrolytes, CBC, TSH, EKG, chest $\mathrm{x}$-ray, and urinalysis were normal and her phenytoin level was in the therapeutic range, unchanged from pre-morbid levels. She had no known history of a Streptococcus infection. Prior to evaluation at our clinic she had been placed on haloperidol $0.5 \mathrm{mg}$ twice a day with some mild improvement in aggressive behaviors, but she was overly sedated and there was concern of decreased seizure threshold with increased doses.

After our evaluation, the haloperidol was discontinued. The patient was placed on a combination of citalopram 20 $\mathrm{mg}$ and risperidone $0.5 \mathrm{mg}$ BID. An SSRI was selected because this medication class is often effective in treating OCD. Risperidone was selected to replace the haloperidol (which had been somewhat helpful in reducing her aggression) because of the lower risk of EPS and TD, and because of its efficacy as an "add-on" therapy in the non-Down syndrome population.

Within three weeks of starting these medications the patient began showing improvement. The checking and ordering symptoms became less prominent, she was no longer physically aggressive and she was better able to tolerate disruption of her daily routine. After six weeks staff saw her as being back at her pre-morbid baseline. Her "sunny disposition" returned and the work and home difficulties dissipated. She tolerated the medications well without any observed side effects, and after 50 months of therapy she has not developed EPS or TD symptoms. Her blood glucose levels have been more stable and she was tapered off phenytoin without the recurrence of seizure activity. Staff noted that she returned to her pre-morbid level of cognitive functioning and she has shown no evidence of cognitive decline since our initial evaluation.

\section{Results}

In this case series, three of the patients developed a significant progression of previously mild repetitive behaviors in the fourth or fifth decade of life. Each of the four patients exhibited co-morbid psychiatric symptoms beyond those of OCD. In each case, pharmacotherapy successfully reduced the co-morbid non-OCD symptoms. In our patient group, two patients were started on an SSRI and risperidone concomitantly because of their co-morbid presenting symptoms. One patient was started on an SSRI alone and experienced reduction in OCD symptoms. Another patient was started on an SSRI alone without reduction in OCD symptoms, but when risperidone was added his OCD symptoms remitted. While mild side effects were noted in two of the patients treated with combination therapy, none developed EPS or TD.

Each patient developed repetitive behaviors or checking behaviors that are consistent with OCD. None reported obsessive thoughts, but given that each patient had cognitive deficits, this was difficult to accurately assess, and thus, observable behaviors were utilized to make the diagnosis of OCD. In each patient over 40 years old, group home staff or family noted some cognitive decline prior to the patient being treated. After treatment, two of these patients returned to their previous level of cognitive functioning, thus excluding a progressive dementia as the etiology of the OCD symptoms in those patients.

\section{Discussion}

Definitively diagnosing OCD in patients with Down syndrome can be difficult in that the DSM-IV-TR (American Psychiatric Association, 2000) diagnosis depends upon adult patients being able to recognize that thoughts or behaviors are excessive or unreasonable. This criterion was not met in each of our patients, or if present, could not be elicited because of the patients' developmental disorder. In children, the criterion of recognition that the obsessions or compulsions are excessive does not apply. McDougle et al., (McDougle et al., 1995) have argued that this criterion is not relevant in autistic patients with repetitive behaviors. Based on our experience with the patients in this case series, we support the contention that this criterion may not need to be present in order to establish an OCD diagnosis in Down syndrome.

The patients described in this article each exhibited symptoms consistent with OCD. Those treated with combination SSRI and risperidone achieved significant reduction in OCD symptoms without the development of side effects. It is interesting that each patient developed OCD symptoms later in life. Particularly in the older patients, advancing Alzheimer's dementia could be a possible explanation, but given that two of the successfully treated patients returned to previous cognitive functioning levels when the OCD was treated, this explanation does not appear plausible in those patients.

The safety of long term neuroleptic exposure in this patient group is a consideration in the clinical decision process. Based upon the small number of patients in this study and the time period of follow up, we cannot conclude that patients with Down syndrome receiving risperidone are not at risk of developing TD. We saw no evidence of TD in any patient, but informed consent provided by guardians 


\begin{tabular}{|c|c|c|c|c|c|c|c|c|c|}
\hline \multirow[t]{2}{*}{ Case } & \multicolumn{4}{|c|}{ MR Status Presenting Problems } & \multirow[b]{2}{*}{ Medications } & \multirow[b]{2}{*}{ Response } & \multirow[b]{2}{*}{ Side effects } & \multirow[b]{2}{*}{$\begin{array}{l}\text { Months on } \\
\text { Neuroleptic }\end{array}$} & \multirow[b]{2}{*}{$\begin{array}{l}\text { EPS } \\
\text { or TD }\end{array}$} \\
\hline & Age & Gender & & & & & & & \\
\hline NR I & 44 & $\mathrm{~F}$ & Mild & $\begin{array}{l}\text { OCD + } \\
\text { aggression }\end{array}$ & $\begin{array}{l}\text { Citalopram 20mg, } \\
\text { Risperdal 0.5mg BID }\end{array}$ & $\begin{array}{l}\text { Remission of OCD } \\
\text { and aggression }\end{array}$ & None evident & 50 months & No \\
\hline MT 2 & 43 & $M$ & Mod & $\begin{array}{l}\text { OCD, } \\
\text { hallucinations }\end{array}$ & $\begin{array}{l}\text { Sertraline } 100 \mathrm{mg} \\
\text { q.am, } \\
\text { Risperdal } 0.5 \mathrm{mg} \\
\text { q.h.s. }\end{array}$ & $\begin{array}{l}\text { Remission of } \\
\text { hallucinations, } \\
\text { improvement in } \\
\text { repetitive behaviors }\end{array}$ & $\begin{array}{l}\text { Sedation from } \\
\text { citalopram which } \\
\text { was discontinued } \\
\text { and sertraline was } \\
\text { then initiated }\end{array}$ & 16 months & No \\
\hline MV 3 & 49 & $M$ & Mod & $\begin{array}{l}\text { OCD, } \\
\text { depression, } \\
\text { aggression }\end{array}$ & $\begin{array}{l}\text { Sertraline } 250 \mathrm{mg} \text {, } \\
\text { Risperdal } 0.5 \mathrm{mg} \text { BID, } \\
\text { Lorazepam } 0.5 \mathrm{mg} \\
\text { BID }\end{array}$ & $\begin{array}{l}\text { Decreased } \\
\text { repetitive } \\
\text { behaviors, } \\
\text { aggression } \\
\text { recurred when } \\
\text { lorazepam was } \\
\text { discontinued }\end{array}$ & Mild sedation & 5 months & No \\
\hline PT 4 & 33 & $M$ & Mild & $\begin{array}{l}\text { OCD + } \\
\text { major } \\
\text { depression }\end{array}$ & Fluoxetine $60 \mathrm{mg}$ & $\begin{array}{l}\text { Depression } \\
\text { improved, no } \\
\text { change in OCD } \\
\text { symptoms }\end{array}$ & $\begin{array}{l}\text { Possible REM } \\
\text { sleep } D / O \\
\text { exacerbation }\end{array}$ & NA & No \\
\hline
\end{tabular}

and ongoing physician monitoring are important facets of treatment.

As sometimes seen in the non-Down syndrome OCD population, one patient's OCD symptoms responded to an SSRI alone, while others showed symptom improvement with combination therapy of an SSRI and risperidone. While this is a small case series, our experience with these patients supports the use of combination pharmacotherapy for OCD in patients with Down syndrome who do not respond to SSRIs alone.

\section{Correspondence}

Bruce Sutor MD - Department of Psychiatry and Psychology, Mayo Clinic, 200 First St SW, Rochester, MN 55905 • e-mail: sutor.bruce@mayo.edu

\section{References}

American Psychiatric Association: Diagnostic and Statistical Manual of Mental Disorders, Fourth Edition, Text Revision (2000). Washington, DC, American Psychiatric Association.

Barak, Y. et al. (1995). Disabling compulsions in 11 mentally retarded adults: an open trial of clomipramine SR. Journal of Clinical Psychiatry, 56, 459-461.

Bodfish, J.W. \& Madison, J.T. (1993). Diagnosis and fluoxetine treatment of compulsive behavior disorder of adults with mental retardation. American Journal on Mental Retardation, 98, 360-367.

Charlot, L. et al (2002). Obsessional slowness in Down's syndrome. Journal of Intellectual Disability Research, 46 , 517-524.

Cook, E.H. et al. (1990). Fluoxetine treatment of borderline mentally retarded adults with obsessive-compulsive disorder. Journal of Clinical Psychopharmacology, 10, 228-229.

Evans, D.W. \& Gray F.L. (2000). Compulsive-like behavior in individuals with Down syndrome: it's relation to mental age level, adaptive and maladaptive behavior. Child Development, 71, 288-300.
Greist, J.H. et al. (1995). Efficacy and tolerability of serotonin transport inhibitors in obsessive-compulsive disorder: a meta-analysis. Archives of General Psychiatry, 52, 53-60.

McDougle, C.J. et al. (1995). A case-controlled study of repetitive thoughts and behavior in adults with autistic disorder and obsessive-compulsive disorder. American Journal of Psychiatry, 152, 772-777.

McDougle, C.J. et al. (2000). A double-blind, placebocontrolled study of Risperidone addition in serotonin reuptake inhibitor-refractory obsessive-compulsive disorder. Archives of General Psychiatry, 57, 794-801.

Myers, B.A. \& Pueschel, S.M. (1991). Psychiatric disorders in a population with Down syndrome. Journal of Nervous and Mental Disease, 79, 609-613.

O’Dwyer, J. (1992). Two cases of obsessive-compulsive disorder in individuals with Down's syndrome. Journal of Nervous and Mental Disease, 180, 603-604.

Prasher, V.P. \& Day, S. (1995). Brief report: ObsessiveCompulsive disorder in adults with Down's syndrome. Journal of Autism and Developmental Disorders, 25, 453-458.

Prasher, V.P. (1995). Prevalence of psychiatric disorders in adults with Down syndrome. European Journal of Psychiatry, 9, 77-82.

Raitasuo, S. et al. (1998). Anorexia nervosa, major depression, and obsessive-compulsive disorder in a Down's syndrome patient. International Journal of Eating Disorders, 23, 107-109.

Wiene, K. \& Lamberti, J.S. (1993). Sertraline and mental retardation with obsessive compulsive disorder. American Journal of Psychiatry, 150, 1270. 